\title{
Biologia e manejo de Plantas Daninhas em Áreas de Plantio DIRETO $^{1}$
}

\author{
Weed Biology and Management in No-Tillage Areas
}

GOMES JR., F.G. ${ }^{2}$ e CHRISTOFFOLETI, P.J. ${ }^{3}$

\begin{abstract}
RESUMO - Procurou-se relacionar alguns aspectos importantes da biologia e do manejo das plantas daninhas infestantes em áreas cultivadas sob sistema de plantio direto, com o objetivo de mostrar que a viabilidade deste plantio depende do controle eficiente das plantas daninhas. Nesse sistema de cultivo ocorrem algumas espécies de plantas daninhas comumente não observadas no sistema convencional, sendo essas constatações relacionadas ao não-revolvimento do solo, favorecendo o desenvolvimento de espécies de plantas daninhas perenes, e às alterações nas condições de temperatura e incidência de luz no interior do solo, influenciando os mecanismos de dormência das sementes de algumas espécies. A estratégia adequada para o controle das plantas daninhas em plantio direto exige conhecimento da dinâmica populacional do banco de sementes do solo e deve reunir métodos integrados de controle para reduzir o uso de herbicidas. A liberação de substâncias alelopáticas de algumas culturas de cobertura e o efeito supressor da camada de palha são medidas importantes para integrar ao controle quimico das plantas daninhas. Entretanto, deve-se atentar para os efeitos negativos sobre algumas espécies de plantas cultivadas. As pesquisas na área de biologia das plantas daninhas e alelopatia das culturas de cobertura, associadas com a tecnologia de aplicação de herbicidas e a agricultura de precisão, poderão contribuir para a otimização do controle das plantas daninhas em áreas de plantio direto.
\end{abstract}

Palavras-chave: semeadura direta, banco de sementes, palhada, glyphosate.

\begin{abstract}
Some important aspects of weed biology and control under no tillage are described to show that the viability of this system depends on weed control efficiently performed. Some of the weeds infesting this cropping system are present in much greater density under the conventional system, this being probably due to the little soil disturbance under no tillage systems, where the occurrence of perennial weeds is more feasible, and changes in the temperature and light incidence on the soil surface influence dormancy of some weed species. Adequate strategy for weed control under the no tillage system requires knowledge on weed seed bank dynamics and must integrate methods of weed control in order to reduce the use of herbicides. The release of alellopathic compounds by some of the cover crops and the suppressive effects of crop residue cover are important measures in order to integrate the chemical control of weeds. However, it is important to be aware of the negative impacts over certain cultivated species of plants. Studies on weed biology and alellopathy of cover crops, associated to herbicide application technology and precision agriculture may contribute to weed control optimization in areas under no tillage system.
\end{abstract}

Keywords: direct seeding, weed seed bank, crop residue, glyphosate.

1 Recebido para publicação em 13.12.2007 e na forma revisada em 30.5.2008.

2 Doutorando do Programa de Pós-graduação em Fitotecnia da ESALQ-USP, <fggjunio@esalq.usp.br>; ${ }^{3}$ Professor Associado do Dep. de Produção Vegetal, ESALQ-USP-LPV, Av. Pádua Dias, 11 - Caixa Postal 09, 134180-900 - Piracicaba-SP. 


\section{INTRODUÇÃO}

Atualmente, no Brasil, cerca de 22 milhões de hectares são ocupados pelo sistema de plantio direto, com expectativa de expansão da área agrícola sob esse sistema. Esse fato deve-se às inúmeras vantagens decorrentes da utilização do plantio direto, como a sustentabilidade agrícola devido à conservação dos recursos naturais e preservação da biodiversidade do solo, podendo aumentar a produtividade das culturas, além, segundo Gajri et al. (2002), da possibilidade de contribuir para a redução do aquecimento global mediante o seqüestro de carbono. Entretanto, para o estabelecimento do sistema de plantio direto são necessários cuidados especificos de gerenciamento, dentre os quais se destaca o eficiente controle das plantas daninhas.

A avaliação das necessidades de controle das plantas daninhas é função da taxa de emergência das espécies presentes no banco de sementes do solo e deve ser estabelecida para cada sistema de manejo da cultura implantada (Voll et al., 2003). Além disso, seria praticamente impossivel estabelecer o sistema de plantio direto como uma prática economicamente viável e ecologicamente correta sem a integração dos métodos de controle das plantas daninhas. Conforme Ruedell (1995), o sucesso dessa operação depende principalmente do planejamento na propriedade, levando-se em conta um sistema de rotação de culturas e não apenas uma cultura isoladamente. Assim, o principal objetivo desta revisão foi discorrer sobre aspectos importantes da biologia e do manejo das plantas daninhas infestantes em áreas de plantio direto.

\section{A biologia das plantas daninhas em áreas de plantio direto pode ser alterada pelas condições de manejo do solo, das culturas e dos métodos de controle}

O não-revolvimento do solo, indispensável em áreas de plantio direto, promove modificações na dinâmica populacional das plantas daninhas. Esse evento está associado a mudanças na composição da comunidade infestante no tempo, considerando o número e a dominância relativa de cada espécie no agroecossistema (Zelaya et al., 1997). Essas modificações envolvem aspectos da biologia e ecologia das espécies e podem ser alteradas pelas condições de manejo do solo, das culturas e dos métodos de controle (Voll et al., 2005), sendo composta por vários fatores (Figura 1). As reservas de sementes viáveis no solo, em profundidade e na sua superficie, são designadas como banco de sementes. Essa porção é uma agregação de sementes não-germinadas, mas potencialmente capazes de substituir plantas adultas anuais que desapareceram por causa natural ou não, ou perenes, suscetíveis a doenças, distúrbios ou consumo por animais (Baker, 1989). Embora a quantidade de sementes de plantas daninhas presentes na camada arável do solo possa variar de 2.000 até 7.000 por metro quadrado, em diferentes agroecossistemas e localidades (Johnson \& Anderson, 1986), a germinabilidade dessas sementes com o decorrer do tempo é variável entre as espécies. Sementes como as de amendoimbravo (Euphorbia heterophylla) e picão-preto (Bidens pilosa) apresentam, de modo geral, alta taxa de germinação e emergência, exaurindose no solo em cerca de três a quatro anos, na ausência de reinfestação (Voll et al., 2001), enquanto outras, como a trapoeraba, podem sobreviver no solo por cerca de 40 anos (Voll et al., 1997).

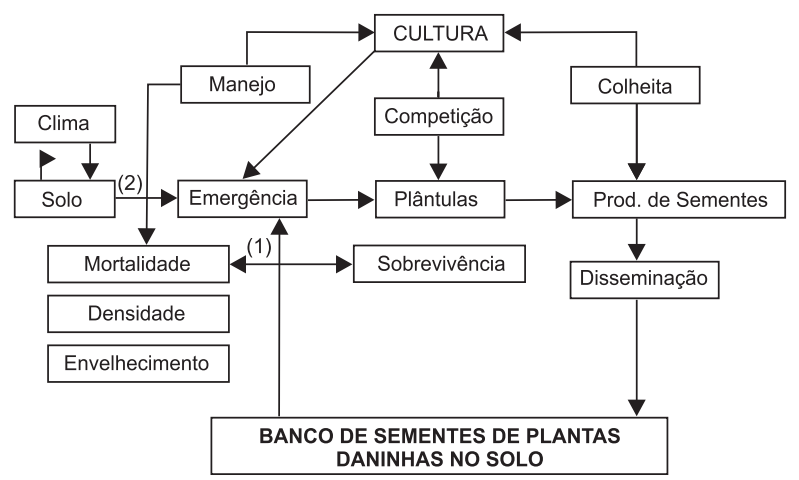

Figura 1 - Fatores componentes da dinâmica de plantas daninhas. Mudanças na comunidade de plantas daninhas podem ser observadas pelo monitoramento do banco de sementes, particularmente se a comunidade de plantas daninhas contém muitas espécies com sementes persistentes. A própria densidade e o envelhecimento natural contribuem para a redução da população de sementes no banco de sementes do solo (1). O clima e o solo alterados pelas condições de manejo afetam as condições de germinação das sementes (2) que podem ou não estar dormentes. 
O número de sementes do banco de sementes no solo em plantio direto é considerado alto, porém a porcentagem de sementes que germina e torna-se competitiva pode ser considerada muito baixa. Segundo Yenish et al. (1992), a concentração das sementes de plantas daninhas em plantio direto diminui de forma logarítmica com o aumento da profundidade do solo. Esses autores observaram que mais de $60 \%$ das sementes de plantas daninhas encontravam-se a $1,0 \mathrm{~cm}$ da superficie do solo. A presença de sementes na camada superficial e o freqüente cultivo predispõem ao esgotamento mais rápido do banco de sementes do solo (Carmona, 1992). Um exemplo disso é a germinação e o decréscimo do número de sementes de picão-preto (Bidens pilosa), que foram mais acentuados na superficie do solo (Carmona $\&$ Villas Bôas, 2001). A maior concentração de sementes na superfície do solo facilita a homogeneidade de emergência das plântulas e a efetividade das medidas de controle, especialmente a ação dos herbicidas (Pitelli \& Durigan, 2003).

\section{As plantas daninhas anuais são predominantes no primeiro ano do plantio direto, $e$ as perenes, nos anos seguintes}

No sistema de plantio direto, os fluxos de germinação das sementes de plantas daninhas são provocados principalmente por alterações de temperatura do solo. Assim, durante o inverno, há diminuição da temperatura do solo, favorecendo a germinação das sementes de algumas plantas daninhas, sendo denominadas espécies de inverno. Por outro lado, durante o verão, ocorre a germinação das sementes de determinadas espécies de plantas daninhas, estimulada pela elevação da temperatura do solo, sendo essas plantas denominadas espécies de verão. Os fluxos subseqüentes possuem relação maior com a precipitação pluvial (Ruedell, 1995). Além disso, tem sido observada alta densidade de plantas daninhas latifoliadas com sementes pequenas (Derksen et al., 1994; Gill \& Arshad, 1995; Tuesca et al., 2001). A predominância deste tipo de planta daninha no sistema de plantio direto pode ser atribuída à intolerância ao distúrbio do solo (Frick \& Thomas, 1992) e à presença de resíduo de cultivo que favoreça a retenção, a germinação e o estabelecimento de plântulas (Feldman et al., 1994).
A população de espécies de plantas daninhas anuais diminui a partir do início do segundo ano de implantação do sistema de plantio direto, quando ocorre tendência de aumento da população de espécies de plantas daninhas perenes (Ruedell, 1995; Gassen \& Gassen, 1996; Buzatti, 1999). Isso ocorre porque os órgãos vegetativos de algumas dessas espécies não são submetidos à dessecação, devido às arações e gradagens predominantes no preparo convencional do solo (Victoria Filho, 1985). Como exemplos, destacam-se a maria-mole (Senecio brasiliensis), a guanxuma (Sida sp.), a tiririca (Cyperus sp.) e a lingua-de-vaca (Rumes sp.). Por outro lado, o aparecimento de algumas plantas daninhas anuais em plantio direto, como o capim-marmelada (Brachiaria plantaginea), o capim-colchão (Digitaria horizontalis), a poaia-branca (Richardia brasiliensis) e o amendoim-bravo (Euphorbia heterophylla), deve-se mais a falhas no controle num sistema de rotação de culturas que à influência do sistema de cultivo (Ruedell, 1995).

\section{Os residuos vegetais predominantes sobre o solo podem exercer efeitos químicos, físicos e biológicos nas plantas daninhas}

A germinação e a emergência das plantas daninhas em plantio direto, devido à presença de resíduos vegetais sobre o solo, podem não ocorrer. Dependendo da espécie de planta de cobertura e da quantidade de palhada existente sobre o solo, o controle das plantas daninhas pode ocorrer devido à liberação de compostos alelopáticos e/ou pelo efeito físico da palhada, associado com a inativação dos mecanismos de dormência ou com a formação de barreira física, impedindo a sobrevivência das sementes germinadas na superficie do solo. Os compostos químicos responsáveis pela alelopatia são denominados aleloquímicos (Souza et al., 2006), e cada espécie pode produzir um conjunto variado dessas substâncias, com ação diferenciada sobre os componentes da comunidade em que está inserida (Putnam et al., 1983), dependendo, principalmente, da quantidade do material vegetal depositado na superfície do solo, do tipo de solo, da população microbiana e das condições climáticas (Pitelli, 1997). Essas substâncias são encontradas em resíduos de plantas ou são produzidas por microrganismos na degradação dos restos culturais no campo 
(Cardina, 1995). Como exemplo, tem-se a ação de microrganismos em glicosídeos cianogênicos presentes em Sorghum halepense, com a produção de duas toxinas: $\mathrm{HCN}$ e benzaldeídos (Putnam, 1985).

Os efeitos físicos da cobertura morta podem ser atribuídos à filtragem da luz, à quantidade e qualidade do comprimento das ondas luminosas e à manutenção da temperatura com menores oscilações (Pitelli, 1997; Theisen \& Vidal, 1999). A luz, a temperatura, a umidade e suas alterações são os mais importantes fatores ambientais para se provocar a superação da dormência das sementes de plantas daninhas (Ruedell, 1995). A cobertura de palha favorece a redução no início do crescimento ativo do embrião das sementes fotoblásticas positivas e de sementes que necessitam de alternância de temperatura para germinar (Paes \& Rezende, 2001). Essa adaptação é considerada um mecanismo natural de defesa das espécies pelo fato de as sementes não germinarem em maiores profundidades no solo, onde a temperatura é sempre mais constante (Carvalho, 1998). O efeito físico da cobertura morta também reduz a sobrevivência de plantas daninhas com pequena quantidade de reservas nas sementes. Segundo Pitelli (1998), muitas vezes, as reservas não são suficientes para garantir a sobrevivência de plântulas no espaço percorrido dentro da cobertura morta, para ter acesso à luz e iniciar o processo fotossintético. A cobertura do solo pode atuar também como barreira física, impedindo a incidência de luz e a realização de fotossíntese por aquelas plântulas que conseguiram emergir do solo (Azania et al., 2002) e dificultando a emergência de várias espécies de plantas daninhas, devido ao sombreamento (Severino \& Christoffoleti, 2001; Constantin et al., 2005) e à conseqüente redução da amplitude térmica do solo (Severino \& Christoffoleti, 2001). No Sul do Brasil, o cultivo de azevém e aveia-preta e o consórcio entre azevém, aveia-preta, centeio, ervilhaca e nabo forrageiro podem contribuir para a redução de infestação de plantas daninhas na cultura do milho. No entanto, em muitas situações ainda há necessidade de intervenção adequada com herbicidas, para evitar a redução de produtividade em função da interferência de plantas daninhas (Balbinot Junior et al., 2007).
Além dos efeitos químicos e físicos, existem os efeitos biológicos, que se devem à interferência dos resíduos vegetais na sobrevivência do banco de sementes. As sementes de plantas daninhas produzidas após a adoção do sistema de plantio direto ficam depositadas na camada superficial do solo, onde estão suscetíveis à ação de predadores de grande porte, como pássaros e roedores (Pitelli, 1997), além de outros animais de pequeno porte, como insetos, moluscos e crustáceos (Kremer \& Spencer, 1989), que danificam fisicamente as sementes, afetando sua viabilidade (Vidal \& Theisen, 1999). Dessa forma, a cobertura de palha propicia condições para a instalação de uma densa microbiocenose na camada superficial do solo, com grande quantidade desses organismos que podem utilizar sementes e plântulas de plantas daninhas como fontes de energia (Pitelli, 1997), provocando a deterioração e a perda da viabilidade de sementes no solo (Vidal \& Theisen, 1999). Por exemplo, durante o ciclo de cultivo de milho, o consumo diário de sementes de Sorghum halepense, por roedores, variou de 3 a $15 \%$ e 1 a $18 \%$ em área de cultivo de soja (Scopel et al., 1988).

\section{O manejo integrado é a melhor estratégia de controle de plantas daninhas em áreas de plantio direto e a rotação de culturas é indispensável}

Para o manejo eficiente de plantas daninhas em plantio direto, devem ser congregados todos os métodos de controle possiveis, ou seja, utilizar-se do manejo integrado de plantas daninhas, compondo estratégia tecnicamente eficiente e economicamente viável para manter a sustentabilidade do sistema (Paes \& Rezende, 2001). Sistemas integrados de manejo têm o potencial para reduzir o uso de herbicidas e proporcionar manejo de plantas daninhas eficiente e prolongado (Swanton \& Weise, 1991; Paes \& Resende, 2001). Trabalhos realizados nos Estados Unidos e no Canadá mostram redução no uso de herbicidas em áreas de plantio direto com mistura de herbicidas ou com a ceifa das plantas daninhas nas entrelinhas. Essas práticas têm sido utilizadas em várias culturas, entre elas o milho e a soja (Donald et al., 2001), e foram eficientes no controle de plantas daninhas utilizando-se do esquema de rotação milho/soja/trigo de inverno em sistema de plantio direto (Swanton et al., 
2002). Segundo Silva (1997), a adoção do sistema de plantio direto, como meio de reduzir o uso de herbicidas e a contaminação ambiental, é viável por várias razões, entre as quais citam-se: o aparecimento, no mercado, de herbicidas modernos, sistêmicos, capazes de dessecar os restos culturais e as plantas daninhas, tanto as anuais quanto as bianuais e perenes, sem ação residual no solo; a formação e acúmulo de palha na superfície do solo, com efeito físico e alelopático sobre a população de plantas daninhas; a redução do processo erosivo do solo, possibilitando redução no risco de contaminação de sedimentos do solo no processo de escorrimento superficial; e o acúmulo de sementes de plantas daninhas na superficie do solo, ficando expostas à ação do clima e de predadores, diminuindo o banco de sementes e a necessidade do uso de herbicidas a cada safra.

No manejo integrado de plantas daninhas em plantio direto, a rotação de culturas é fator preponderante e indispensável. Esta técnica permite o controle de muitas espécies de plantas daninhas que vegetam em sincronismo com as culturas (Lorenzi, 1986; Paes \& Rezende, 2001). Existem evidências da redução da infestação de plantas daninhas com a utilização da rotação de culturas em lavouras, por exemplo, de cana-de-açúcar (Christoffoleti, 1988; Ferreira, 1988) e de trigo (Ruedell, 1995). Resultados de pesquisa revelam que a rotação de culturas associada ao controle químico é eficiente no controle de capim-carrapicho (Cenchrus echinatus), capim-amargoso (Digitaria insularis), capim-colchão (Digitaria horizontalis), capim-marmelada (Brachiaria plantaginea) e guanxuma (Sida rhombifolia). As espécies beldroega (Portulaca oleraceae), ervaquente (Spermacoce latifolia) e caruru (Amaranthus viridis), que ocorreram no primeiro ano de plantio direto, tiveram suas infestações diminuídas significativamente após quatro anos nesse sistema. Contudo, dependendo das culturas em rotação e da respectiva combinação cronológica de cultivo, a dinâmica das plantas daninhas pode apresentar alterações mais ou menos significativas, causando efeitos diferenciados sobre a caracterização da comunidade infestante da área de cultivo (Pereira \& Velini, 2003). Portanto, para que os objetivos sejam alcançados, o programa de rotação de culturas deve ser bem elaborado, associando-se a um programa de uso simultâneo de herbicidas, métodos culturais, capinas mecânicas e mesmo métodos biológicos, visando melhorar a eficiência e o espectro de plantas daninhas controladas a custos reduzidos (Ruedell, 1995). Dessa maneira, os sistemas de rotação de culturas devem ser programados de maneira que interrompam o ciclo biológico das plantas daninhas mais comuns numa determinada área (Santos \& Reis, 1991).

\section{Os herbicidas são altamente eficientes no controle de plantas daninhas em plantio direto, mas podem favorecer o desenvolvi- mento de biótipos resistentes}

Com a adoção do sistema de plantio direto, o controle químico ganhou importância em substituição ao controle realizado por meio de arações e gradagens, no cultivo convencional. No início dos anos 70 , houve a introdução do glyphosate, que possibilitou o controle eficiente das plantas daninhas em pós-emergência (Velloso \& Souza, 1993). No entanto, estudos realizados recentemente sobre resistência de plantas daninhas a esse herbicida (Roman et al., 2004; Vargas et al., 2005) evidenciaram que o seu uso freqüente pode favorecer o desenvolvimento de plantas daninhas resistentes, particularmente em lavouras com plantas transgênicas, caso o produto não seja bem manejado. Segundo Monquero \& Christoffoleti (2003), aplicações repetidas de glyphosate podem modificar a composição específica de plantas daninhas da área de cultivo e favorecer a predominância de espécies tolerantes, como Commelina benghalensis, Ipomoea grandifolia e Richardia brasiliensis. Dessa forma, embora seja um método eficiente de eliminar as plantas daninhas, se usado de maneira inadequada, o controle químico pode onerar o custo de produção e/ou não apresentar eficácia.

$O$ adequado controle químico de plantas daninhas no plantio direto deve ser realizado em pré e pós-semeadura. No primeiro caso, as plantas daninhas são eliminadas antes da implantação das culturas. Essa operação substitui o efeito do preparo do solo na eliminação das plantas daninhas. Nesta fase, também chamada de operação de manejo, geralmente são utilizados herbicidas de ação total (Tabela 1). Em pós-semeadura, utilizam-se os mesmos herbicidas recomendados para o sistema 
Tabela 1 - Alternativas de uso de herbicidas para a aplicação em pré-semeadura, visando o controle de plantas daninhas mono e dicotiledôneas no sistema de plantio direto

\begin{tabular}{|c|c|c|c|}
\hline $\begin{array}{c}\text { Planta daninha } \\
\text { controlada }\end{array}$ & Herbicida & Dosagem (g i.a ha $\left.{ }^{-1}\right)$ & $\begin{array}{l}\text { Aplicação antes da } \\
\text { semeadura }\end{array}$ \\
\hline \multirow{3}{*}{$\begin{array}{l}\text { Monocotiledôneas } \\
\text { anuais pouco } \\
\text { desenvolvidas }\end{array}$} & paraquat & 200 a 400 & 3 a 5 dias \\
\hline & paraquat + diuron & $200+100$ a $400+200$ & 3 a 5 dias \\
\hline & glyphosate & 480 a 720 & 3 a10 dias \\
\hline \multirow{3}{*}{$\begin{array}{l}\text { Dicotiledôneas anuais } \\
\text { pouco desenvolvidas }\end{array}$} & $2,4-\mathrm{D}$ & 400 a 800 & 10 dias \\
\hline & paraquat + diuron & $300+150$ a $400+200$ & 3 a 5 dias \\
\hline & glyphosate & 480 a 720 & 3 a10 dias \\
\hline \multirow{4}{*}{$\begin{array}{l}\text { Monocotiledôneas e } \\
\text { dicotiledôneas anuais } \\
\text { desenvolvidas e } \\
\text { perenes }\end{array}$} & paraquat + diuron e 2,4-D & $400+200$ a $600+300$ e 600 a 800 & 10 dias \\
\hline & glyphosate $+2,4-\mathrm{D}$ & $600+800$ a $840+1120$ & 10 dias \\
\hline & glyphosate & 720 a 1440 & 3 a 10 dias \\
\hline & $\begin{array}{c}\text { paraquat + diuron } \\
\mathrm{e} \\
\text { paraquat }+ \text { diuron } \\
\text { (aplicação seqüencial) }\end{array}$ & $\begin{array}{c}300+150 \text { a } 400+200 \\
\text { e } \\
200+100 \text { a } 300+150\end{array}$ & $\begin{array}{l}10 \text { dias } \\
\mathrm{e} \\
3 \text { dias }\end{array}$ \\
\hline
\end{tabular}

Fonte: Ruedell (1995)

convencional, incluindo-se os pré e os pósemergentes, excluindo-se, evidentemente, os que necessitam de incorporação (Ruedell, 1995).

Uma das dificuldades do manejo de plantas daninhas em áreas de plantio direto consiste na ineficiência dos herbicidas devido à densa cobertura morta. A presença de resíduos de plantas na superfície do solo após a dessecação, em pré-semeadura, pode diminuir a ação dos herbicidas aplicados em pré-emergência, devido à interrupção do movimento destes até o solo, atribuída principalmente à retenção e / ou possibilidade de degradação e volatilização do herbicida interceptado (Johnson et al., 1989; Locke \& Bryson, 1997). A diferença entre a maior e menor retenção dos herbicidas pela palhada pode ser atribuída às diferentes solubilidades e pressões de vapor dos produtos, às quantidades e origem da cobertura morta e à intensidade e época de ocorrência de chuvas após a aplicação dos produtos (Fornarolli et al., 1998). Outra dificuldade do controle químico é a dessecação antecedendo a semeadura direta. O grau de cobertura do solo e a velocidade de dessecação da biomassa das plantas daninhas podem prejudicar o desenvolvimento inicial das culturas, dependendo da época em que se faz o manejo. Em áreas com grande cobertura vegetal, as culturas do milho e da soja, semeadas em períodos muito curtos após a dessecação (sete dias) e no sistema aplique-plante, apresentaram clorose das folhas no período inicial, com redução do desenvolvimento vegetativo e da produtividade (Constantin \& Oliveira Junior, 2005). A semeadura do milho logo após a dessecação da aveia pode acarretar desuniformidade de germinação e desenvolvimento inicial inadequado (estiolamento) das plântulas (Calegari et al., 1998). Em áreas com soja foi observada diminuição da produtividade em até $14 \%$ quando a semeadura ocorreu imediatamente após a dessecação de sorgo (Peixoto $\&$ Souza, 2002) e redução de 243 a $526 \mathrm{~kg} \mathrm{ha}^{-1}$ na produtividade quando o manejo das plantas daninhas foi realizado na data da semeadura e dez dias antes, comparativamente ao manejo antecipado (Oliveira Junior et al., 2006). Em algumas situações, quando há alta infestação de plantas daninhas ou predominâncias de espécies consideradas de difícil controle, são indicadas as aplicações seqüenciais de herbicidas, iniciadas 15 a 20 dias antes da semeadura. Constantin \& Oliveira Junior (2005) enfatizaram que trabalhos com aplicações seqüenciais onde foram aplicados antecipadamente herbicidas sistêmicos, como glyphosate e 2,4-D, e, após 15 a 20 dias (na véspera ou na data da semeadura), herbicidas de contato, como 
paraquat, paraquat + diuron, diquat e flumioxazin, proporcionaram maior eficiência no controle das plantas daninhas e permitiram a semeadura no limpo.

Além da aplicação de herbicidas para controle de infestações na época da semeadura e durante o ciclo das culturas, há também necessidade de realizar o manejo das plantas daninhas após a colheita para eliminar as plantas remanescentes, antes que produzam sementes e causem reinfestação da área de cultivo. No manejo de plantas daninhas em pós-colheita, a indicação é aguardar duas a três semanas após a colheita para que ocorra a germinação da sementeira superficial e das plantas daninhas tigüeras da cultura, o crescimento das plantas daninhas e a brotação ou recuperação daquelas cortadas na colheita (Gassen \& Haas, 2001). Esperar esse período após a colheita para realizar a dessecação é fundamental para eficácia do herbicida, devido à necessidade de as plantas daninhas estarem com área foliar suficientemente desenvolvida, de maneira que o produto seja absorvido em quantidade suficiente que determine a morte das plantas. Além disso, deve-se utilizar colheitadeira com espalhador de palha, sem picador, para distribuir uniformemente os restos culturais, permitindo rápido reposicionamento das folhas das plantas daninhas.

\section{Manejo de plantas daninhas em sistema de plantio direto sem o uso de herbicidas}

O manejo de plantas daninhas em sistema de plantio direto sem o uso de herbicidas é um dos grandes desafios da atualidade. Para que seja executável, é preciso estabelecer um conjunto de práticas, que vão desde a recuperação da fertilidade dos solos, com a diminuição da população das plantas daninhas e melhora na competitividade das culturas, até o controle manual localizado das plantas daninhas.

Segundo Darolt \& Skora Neto (2002), nessas condições de cultivo, dois aspectos devem ser considerados no controle de plantas daninhas: o primeiro consiste na substituição dos herbicidas dessecantes pelo uso de plantas com grande capacidade de abafamento das plantas daninhas, para formação da cobertura morta, que são roladas na fase de formação de grãos (aveia-preta, centeio, aveia-preta + ervilhaca- comum) ou são deixadas completar o ciclo (azevém, ervilhaca-peluda); e o segundo diz respeito à substituição dos herbicidas na cultura por capina manual (catação) ou roçada, aliadas a outras práticas culturais de manejo, entre as quais Kliewer (2004) cita o controle da frutificação das plantas daninhas, a eliminação de pousios entre culturas, a rotação de culturas e a escolha de espécies e variedades agressivas e competitivas com as plantas daninhas, com efeito alelopático e supressor. Outras recomendações, como a semeadura antecipada da cultura para ganhar a concorrência com as plantas daninhas, a manutenção de espessa cobertura de palha sobre o solo, o uso de máquinas que permitam o corte apropriado da palha, com pouco revolvimento do solo na linha de semeadura e a deposição da semente em contato com o solo (Skora Neto, 1998), e o uso de sementes com alta qualidade, para favorecer o rápido e uniforme estabelecimento da cultura, também são importantes medidas para o manejo de plantas daninhas em sistema de plantio direto sem o uso de herbicidas.

\section{CONSIDERAÇÕES FINAIS E PERSPECTIVAS}

Para controle efetivo das plantas daninhas predominantes em áreas sob sistema de plantio direto, é preciso amplo conhecimento da biologia das espécies e das interferências do meio ambiente sobre a dinâmica populacional do banco de sementes do solo. As estratégias de controle devem ser elaboradas para cada caso particular, buscando sempre a integração dos métodos de controle. A rotação de culturas, associada ao controle químico, é indispensável para o controle das plantas daninhas em áreas de plantio direto. Entretanto, devem ser tomados cuidados peculiares quanto aos efeitos alelopáticos nocivos de algumas plantas de cobertura sobre o desenvolvimento de espécies cultivadas. Cuidados específicos também devem ser tomados com relação ao uso do glyphosate para evitar o desenvolvimento de biótipos resistentes, que podem aumentar em cultivos sucessivos de plantas geneticamente modificadas resistentes a esse herbicida.

Inúmeras tecnologias têm sido desenvolvidas tentando obter maior eficiência na aplicação de herbicidas e redução dos impactos no meio ambiente, dentre as quais pode-se citar a definição de unidades de gerenciamento 
diferenciado para aplicação de herbicidas (Tellaeche et al., 2008). Entretanto, grande parte das pesquisas associadas à agricultura de precisão no controle de plantas daninhas tem sido realizada no exterior. Os estudos na área de biologia das plantas daninhas e alelopatia das culturas de cobertura, associados com a tecnologia de aplicação de herbicidas e a agricultura de precisão, poderão contribuir para a otimização do controle das plantas daninhas em áreas de plantio direto.

\section{LITERATURA CITADA}

AZANIA, A. A. P. M. et al. Interferência da palha de canade-açúcar (Saccharum spp.) na emergência de espécies de plantas daninhas da família Convolvulaceae. Planta Daninha, v. 20, n. 2, p. 207-212, 2002.

BAKER, H. G. Some aspects of the natural history of seed banks. In: LECK, M. A.; PARKER, V. T.; SIMPSON, R. L. (Eds.). Ecology of soil seed banks. London: Academic Press, 1989. p. 5-19.

BALBINOT JUNIOR, A. A; MORAES, A.; BACKES, R. L. Efeito de coberturas de inverno e sua época de manejo sobre a infestação de plantas daninhas na cultura de milho. Planta Daninha, v. 25, n. 3, p. 473-480, 2007.

BUZATTI, W. J. S. Controle de plantas daninhas no sistema plantio direto na palha. In: PAULETTI, V.; SEGANFREDO, R. (Coords.). Plantio direto: atualização tecnológica. São Paulo: Fundação Cargill, Fundação ABC, 1999. p. 97-111.

CALEGARI, A. et al. Culturas, sucessões e rotações. In: Sistema plantio direto - o produtor pergunta, a Embrapa responde. Dourados: Embrapa-CPAO, 1998. p. 59-80. (Coleção 500 perguntas 500 Respostas).

CARDINA, J. Biological weed management. In: SMITH, A. E. (Ed.). Handbook of weed management systems. New York: Marcel Dekker, 1995. p. 279-342.

CARMONA, R. Problemática e manejo de bancos de sementes de invasoras em solos agrícolas. Planta Daninha, v. 10, n. $1 / 2$, p. $5-16,1992$

CARMONA, R.; VILLAS BÔAS, H. D. C. Dinâmica de sementes de Bidens pilosa no solo. Pesq. Agropec. Bras. v. 36, n. 3, p. 457-463, 2001.

CARVALHO, F. T. Dormência de sementes de plantas daninhas. In: RESULTADOS DE PESQUISAS, 11., 1998, Ilha Solteira. Palestras... Ilha Solteira: UNESP, 1998. p. 7692 .

Planta Daninha, Viçosa-MG, v. 26, n. 4, p. 789-798, 2008
CHRISTOFFOLETI, P. J. Controle de Brachiaria

decumbens Stapt e de Cyperus rotundus $\mathrm{L}$. em área com cana-de-açúcar (Saccharum spp.) através da técnica de rotação com amendoim (Arachis hypogea L.) integrada ao uso de herbicidas. 1988. $117 \mathrm{f}$. Dissertação (Mestrado em Agronomia) - Escola Superior de Agricultura Luiz de Queiroz, Piracicaba, 1988.

CONSTANTIN, J. et al. Dessecação em áreas com grande cobertura vegetal: alternativas de manejo. Inf. Agron., n. 111, p. 7-9, 2005.

CONSTANTIN, J.; OLIVEIRA JUNIOR, R. S. Dessecação antecedendo a semeadura direta pode afetar a produtividade. Inf. Agron., n. 109, p. 14-15, 2005.

DAROLT, M. R.; SKORA NETO, F. Sistema de plantio direto em agricultura orgânica. R. Plantio Direto, n. 70, p. $28-31,2002$

DERKSEN, D. A. et al. Impact of agronomic practices on weed communities: Fallow within tillage systems. Weed Sci., v. 42, n. 2, p. 184-194, 1994.

DONALD, W. W.; KITCHEN, N. R.; SUDDUTH, K. A. Between-row mowing + banded herbicide to control annual weeds and reduce herbicide use in no-till soybean (Glycine max) and corn (Zea mays). Weed Technol., v. 15, n. 3, p. $675-684,2001$

FELDMAN, S. R.; VESPRINI, J. L.; LEWIS, J. P. Survival and establishment of Carduus acanthoides L. Weed Res., v. 34, n. 4 , p. $265-273,1994$.

FERREIRA, A. C. M. Análise de alternativas de produção de culturas anuais em rotação com a cana-deaçúcar, na região de Ribeirão Preto, São Paulo, 1988. 127 f. Tese (Doutorado em Agronomia) - Universidade Federal de Viçosa, Viçosa-MG, 1988.

FORNAROLLI, D. A. et al. Influência da cobertura morta no comportamento do herbicida atrazine. Planta Daninha, v. 16, n. 2 , p. $97-107,1998$.

FRICK, B.; THOMAS, A. G. Weed surveys in different tillage systems in southwestern Ontario field crops. Can. J. Plant Sci., v. 72, n. 4, p. 1337-1347, 1992.

GAJRI, P. R.; ARORA, V. K.; PRIHAR, S. S. Tillage for sustainable cropping. New York: The Haworth Press, 2002. 195 p.

GASSEN, D. N.; GASSEN, F. R. Plantio direto, o caminho do futuro. 2.ed. Passo Fundo: Aldeia Sul, 1996 207 p. 
GASSEN, D. N.; HAAS, F. D. Manejo de plantas daninhas pós-colheita. R. Plantio Direto, n. 62, p. 14-15, 2001.

GILL, K. S.; ARSHAD, M. A. Weed flora in the early growth period of spring crops under conventional, reduced and zero tillage systems on a clay soil in northern Alberta, Canada. Soil Till. Res., v. 33, n. 1, p. 65-79, 1995.

JOHNSON, M. D.; WYSE, D. L.; LUESCHEN, W. E. The influence of herbicide formulation on wed control in four tillage systems. Weed Sci., v. 37, n. 1, p. 239-249, 1989.

JOHNSON, R. G.; ANDERSON, R. C. The seed bank of tall grass prairie in Illinois. Am. Midland Natural., v. 115, n. 1, p. $123-130,1986$.

KLIEWER, I. Alternativas de controle de plantas daninhas em sistema de plantio direto sem herbicidas. In: SISTEMA AGRÍCOLA SUSTENTÁVEL COM COLHEITA ECONÔMICA MÁXIMA, 1., 2004, São Pedro.

Palestras... São Pedro: 2004. CD-ROM.

KREMER, R. J.; SPENCER, N. R. Impact of a seed-feeding insect and microorganisms on velvetleaf (Abutilon theophrasti) seed viability. Weed Sci., v. 37, n. 2, p. 211 216, 1989.

LOCKE, M. A.; BRYSON, C. T. Herbicide-soil interaction in reduced tillage and plant residue management systems. Weed Sci., v. 45, n. 2, p. 307-320, 1997.

LORENZI, H. Manual de identificação e controle de plantas daninhas: plantio direto e convencional. Nova Odessa: [s.n.], 1986. 220 p.

MONQUERO, P. A.; CHRISTOFFOLETI, P. J. Dinâmica do banco de sementes em áreas com aplicação freqüente do herbicida glyphosate. Planta Daninha, v. 21, n. 1, p. 63-69, 2003.

OLIVEIRA JUNIOR, R. S. et al. Interação entre sistemas de manejo e de controle de plantas daninhas em pós-emergência afetando o desenvolvimento e a produtividade da soja.

Planta Daninha, v. 24, n. 4, p. 721-732, 2006.

PAES, J. M. V.; REZENDE, A. M. Manejo de plantas daninhas no sistema plantio direto na palha. Inf. Agropec., v. 22, n. 208 , p. $37-42,2001$.

PEIXOTO, M. F.; SOUZA, I. F. Efeitos de doses de imazamox e densidades de sorgo (Sorghum bicolor (L.) Moench) em soja (Glycine $\max ($ L.) Merr.) sob plantio direto. Ci. Agrotec., v. 25, n. 2, p. 252-258, 2002.

PEREIRA, F. A. R.; VELINI, E. D. Sistemas de cultivo no cerrado e dinâmica de populações de plantas daninhas. Planta Daninha, v. 21, n. 3, p. 355-363, 2003.
PITELLI, R. A. Dinâmica de plantas daninhas no sistema de plantio direto. In: SIMPÓSIO SOBRE HERBICIDAS E PLANTAS DANINHAS, 1., 1997, Dourados. Resumos... Dourados: Embrapa-CPAO, 1997. p. 50-61.

PITELLI, R. A.; DURIGAN, J. C. Plantas daninhas no sistema de plantio direto de culturas anuais. In: ENCONTRO SUL-MINEIRO SOBRE PLANTIO DIRETO, 1., 2003, Lavras, MG. Anais... Lavras: 2003. CDROM.

PITELLI, R. Plantas daninhas no sistema plantio direto de culturas anuais. R. Plantio Direto, n. 4, p. 13-18, 1998.

PUTNAM, A. R.; DEFRANK, J.; BARNES, J. P. Explotation of allelopathy for weed control in annual and perennial cropping systems. J. Chem. Ecol., v. 9, n. 8, p. 1001-1010, 1983.

PUTNAN, A. R. Weed allelopathy. In: DUKE, S. O. (Ed.). Weed physiology. Boca Raton: CRC Press, 1985. p. 131155 .

ROMAN, E. S. et al. Resistência de azevém (Lolium multiflorum) ao herbicida glyphosate. Planta Daninha, v. 22 , n. 2 , p. 301-306, 2004.

RUEDELL, J. Plantio direto na região de Cruz Alta. Cruz Alta: FUNDACEP FECOTRIGO, 1995. 134 p.

SANTOS, H. P.; REIS, E. M. Efeitos de culturas de inverno sobre o rendimento de grãos e sobre a estatura de plantas da soja. Pesq. Agropec. Bras., v. 26, n. 5, p. 729-735, 1991.

SEVERINO, F. J.; CHRISTOFFOLETI, P. J. Efeitos de quantidades de fitomassa de adubos verdes na supressão de plantas daninhas. Planta Daninha, v. 19, n. 2, p. 223-228, 2001.

SILVA, J. B. Plantio direto: redução dos riscos ambientais com herbicidas. In: SATURNINO, H. S.; LANDERS, J. N. (Eds.). $\mathrm{O}$ meio ambiente e o plantio direto. Brasília: APDC, 1997. p. 83-88.

SKORA NETO, F. Manejo de plantas daninhas. In: Plantio direto: pequena propriedade sustentável. Ponta Grossa: IAPAR, 1998. p. 127-157. (Circular, 101).

SOUZA, L. S. et al. Efeito alelopático de capim-braquiária (Brachiaria decumbens) sobre o crescimento inicial de sete espécies de plantas cultivadas. Planta Daninha, v. 24, n. 4, p. $657-668,2006$.

SWANTON, C. J. et al. Evaluation of alternative weed management systems in a no-till corn-soybean-winter wheat rotation: weed densities, crop yield, and economics.

Weed Sci., v. 50, n. 4, p. 504-511, 2002. 
SWANTON, C. J.; WEISE, S. F. Integrated weed management: the rationale and approach. Weed Technol., v. 5, n. 3 , p. $657-663,1991$.

TELLAECHE, A. et al. A vision-based method for weeds identification through the Bayesian decision theory. Pattern Recognit., v. 41, n. 2, p. 521-530, 2008

THEISEN, G; VIDAL, R. A. Efeito da cobertura do solo com resíduos de aveia-preta nas etapas do ciclo de vida do capim marmelada. Planta Daninha, v. 17, n. 2, p. 189-196, 1999.

TUESCA, D.; PURICELLI, E.; PAPA, J. C. A long-term study of weed flora shifts in different tillage systems. Weed Res., v. 41, n. 4, p. 369-382, 2001.

VARGAS, L. et al. Alteração das características biológicas dos biótipos de azevém (Lolium multiflorum) ocasionada pela resistência ao herbicida glyphosate. Planta Daninha, v. 23 , n. 1, p. 153-160, 2005.

VELLOSO, J. A. R. O; SOUZA, R. O. Plantas daninhas no sistema de plantio direto na palha. In: Plantio direto no Brasil. Passo Fundo: Embrapa-CNPT, FUNDACEPFECOTRIGO, Fundação Abc, 1993. p. 61-75.

VICTORIA FILHO, R. Potencial de ocorrência de plantas daninhas em plantio direto. In: FANCELLI, A. L.; TORRADO, P. V.; MACHADO, J. (Coords.). Atualização em plantio direto. Campinas: Fundação Cargill, 1985. p. $31-48$.
VIDAL, R. A.; THEISEN, G. Efeito da cobertura do solo sobre a mortalidade de sementes de capim-marmelada em duas profundidades no solo. Planta Daninha, v. 17, n. 3, p. 339-344, 1999

VOLL, E. et al. A dinâmica das plantas daninhas e práticas de manejo. Londrina: Embrapa Soja, 2005. 85 p. (Documento, 260).

VOLL, E. et al. Amostragem do banco de semente e flora emergente de plantas daninhas. Pesq. Agropec. Bras., v. 38, n. 2, p. 211-218, 2003.

VOLL, E. et al. Dinâmica de um banco de sementes de plantas daninhas sob diferentes manejos do solo. Planta Daninha, v. 19, n. 2, p. 171-178, 2001.

VOLL, E.; KARAM, D.; GAZZIERO, D. L. P. Dinâmica de populações de trapoeraba (Comelina benghalensis L.) sob manejos de solo e de herbicidas. Pesq. Agropec. Bras., v. 32, n. 6, p. $571-578,1997$.

YENISH, J. P.; DOLL, J. D.; BUHLER, D. D. Effects of tillage on vertical distribution and viability of weed seed in soil. Weed Sci., v. 40, n. 3, p. 429-433, 1992.

ZELAYA, I. A.; OVEN, M. D. K.; PITTY, A. Effect of tillage and environment on weed population dynamics in the dry tropics. Ceiba, v. 38, n. 2, p. 123-135, 1997. 